\title{
Fiscal Expenditure and Education Quality in China: A Regional Heterogeneity Analysis
}

\author{
Yiyang Chen \\ Shanghai Foreign Language School Affiliated to SISU \\ Fuxin Zhang \\ Zhongnan University of Economics and Law
}

\begin{abstract}
In this paper, we explore whether fiscal input brings the raise of regional education quality. To discuss this relationship, we employ Chinese provincial panel data ranged from 2008-2016. By constructing a two-way fixed effect model, we find that provincial education quality is positively associated with the fiscal expenditure, and more specifically, educational expenditure. This correlation is robust even we consider other important factors such economy growth, industrial structure and population structure. Besides, since the regional heterogeneity across China, the relationship between fiscal spending, and education quality may exhibit different patterns, we thus split our samples into eastern region and non-eastern region. Empirical results indicate that our main argument only exists in non-eastern area, which refers to the western area, where expanding fiscal expenditure would be more efficient for the government to raise provincial education quality. Meanwhile, fiscal policy would be less efficient to raise education quality for eastern area, thus new policy instrument is necessary.
\end{abstract}

Keywords: fiscal expenditure, education quality, China, regional heterogeneity analysis

\section{Introduction}

In our modernized world, economy relies heavily on human capital, for production and innovation alike. Greater human capital betokens higher efficiencies of work and lower costs (saving raw material and reducing pollution) in industries, leading to a general economic growth and an overall rise in social welfare. Therefore, countries and regional economies compete to acquire human capital.

Promoting education, whether fundamental or advanced, has been recognized as one of the key and most widely used tools available to governments to increase human capital. Economists view education that raise workers' human capital and productivity as a form of investment, a decision to spend funds or time now because it pays off in the future. As a result, in face of issues concerning shortage of skillful workers, or human capital, governments usually decide to raise fiscal expenditure, the primary and often the only resolution.

It is often taken for granted that higher fiscal expenditure on education would increase education quality (represented by citizens' average years of education), and thus human capital. However, this correlation might not be constantly obvious.

A casual examination of fiscal expenditure on education and number of enrolled students in middle school and high school reveals the potential instability of correlation between fiscal expenditure and education quality. While fiscal expenditure on education of Shanghai increased hugely by $23.8 \%$ from 2013 to 2016, number of enrolled students in high school rise by only $0.64 \%$, and more surprisingly number of enrolled students in middle school dropped by $5.4 \%$ (despite a $3.13 \%$ natural population growth rate). 
Chart 1: Education Expenditure and Number of Enrolled Students in Shanghai

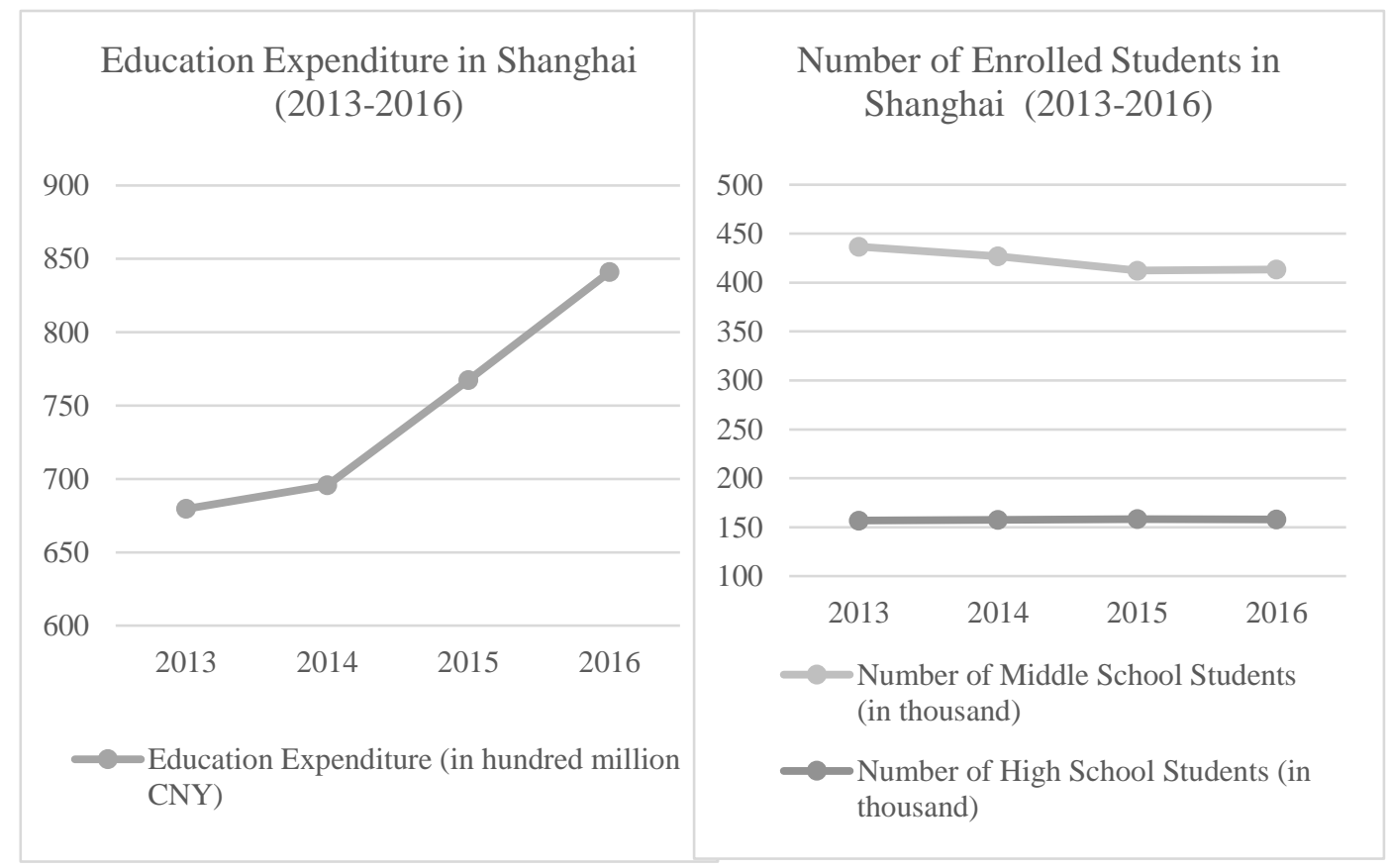

Source: National Bureau of Statistics of China

Therefore, this correlation requires further studies.

Our study examines this correlation between government's education expenditure and level of education by constructing an econometric model to analyze data from 31 provincial districts in China during a period of 20082016.

Indeed, we found a significant correlation between the two variables - fiscal expenditure on education and level of education (represented by average education years of citizens), and this correlation is robust even when previously controlled variables are included in the model.

However, as we split data geographically --into more developed eastern region of China and less developed western region -- it seems, while the correlation is especially significant in western region, it is in fact insignificant in eastern region.

Therefore, we concluded that effective increases in education level resulting from raising fiscal expenditure on education vary from case to case. In regions where fiscal expenditure on education is less efficient, governments should be advised to elevate level of education by other policy instruments.

\section{Literature Review}

It is commonly recognized that education acts as one of the essential instrument to improve human efficiencies at work, and, in a broader perspective, achieve economic growth. Examining the matter at a fundamental level, education betters our economy and augments growth by facilitating the accumulation of human capital, which refers to the amalgamation of individuals' knowledge and abilities which determine their course of action. (Coleman, 1998). As an industry generating vast positive externalities that enable societies to achieve the desired objectives of social and economic development, governments are naturally encouraged to subsidize education industry by injecting more fiscal expenditure. Studies reveals that investment in human capital through training and education are the driving force behind increases in productivity and 
competitiveness at the organizational level (Black and Lynch, 1996), and by enabling increases in human input in the forms of physical and intellectual effort. (Cannon, 2000)

According to existing literature, the relationship between education and economic growth is well discussed. Liang Ji probes how economic growth relates to per capita years of education in his "Relationship between average years of education and economic growth: research based on optimized CD" (2014), and reached the conclusion that there's a solid relationship based on a specialized model. A large number of academic authors, including Blundell, Dearden, Meghir and Sianesi (1999), Slaugter and Rhoades (2004), Liu and Armer (1993), and Reynolds and Ross (1998) share similar perspective. More specifically, some literature analyze the relationship in a specified region, draw more insightful conclusions and provide detailed possible applications. Hong-Sang wrote "The impact of public education expenditure on human capital, growth, and poverty in Tanzania and Zambia: a general equilibrium approach" (2003) based on his examination of how education expenditure associates with social improvement, including economy, employment, etc. Other studies on education correlate rather loosely to the our discussion - the relationship between education expenditure and education quality/level. Some topic includes Sun and Liu's "Measurement of Education Equity between Regions and Genders in China" (2014), which discusses average years of education influenced by regional development and gender bias, and Nieto's "Affirming diversity: the sociopolitical context of multicultural education" (1992), which targets the influence of multicultural to successful education.

Another relevant key focus of existing literature falls on the government actions related to fiscal expenditure on education. Papers of such studies often discuss the efficiency of education expenditure and its subtle implications. Journal of Shandong Institute of Business and Technology publishes Qiao Li and Yanjing Hu's paper in 2016, considering it as "especially focused" analysis originating from an innovative approach to explore the expenditure efficiency. In the paper, Li and Hu discovered crucial determinants of expenditure efficiency -- the quantity of increased teaching facilities and teaching faculty. On the other hand, Joaquim V. Levy and Benedict Clements portrayed a broader picture of education expenditure and captures the impact of public education expenditure on private investment (a far-reaching and specific economic factor) in "Public education expenditure and private investment in developing countries" (1996)

As mentioned in the previous section, the relationship between education expenditure and level of education is often taken for granted, without the support of data. Existing literature often suggest to "increase fiscal expenditure on education, and draft new plans to support both basic and higher education" (Gupta, 2002) in response to the want of human capital. The relationship to be discussed in our paper seems to be a missing link, since there are currently no studies that discuss, directly and in detail, the correlation between education expenditure and education level.

\section{Data \& Summary Statistics}

In this study, we compile our data set from several databases. We adopted the key data in our study from Tai'an CSMAR Database - the largest professional database in China for economic and financial information built by the only Chinese data provider recognized by Wharton Research Service System in greater China region. We take the following data found in CSMAR database directly into our analysis: per capita education expenditure, technology expenditure, culture and sports and media expenditure, social security and employment expenditure, transportation expenditure, and general services expenditure.

In addition, we obtained several data sets from EPS Database, which includes per capita GDP, GDP percentage of industrial sector, GDP percentage of service sector, population of provinces, school enrolments, quantity of high schools, studentfaculty ratio, and child dependency ratio. And per capita disposable income was found in National Bureau of Statistics of China. These data will help to back up our examinations, and provide a more comprehensive angle of analysis.

According to the existing literature, a common proxy for education level or quality is the average years of education of a country's citizens. Our paper adopted this approach. Based on Fan, Peng, and Liu's (2016) method of calculating average years of education, i.e.eduyear $=$ number of elementary school students $\times 6+$ number of middle school students $\times 10.5+$ number of high school students $\times 16$, the key explained variable is represented by accessible data.

Among the controlled variables, per capita expenditure in technology, per capita expenditure in culture and media, per capita expenditure in social security and employment, per capita expenditure in transportation, and per capita expenditure in public services are introduced to control expenditure structures in provinces. Percentage of industrial sector in GDP and 
percentage of service sector are the controlled variables for provincial economic structure. Moreover, we assess provincial economic development level and citizens' living standard by considering the natural logarithm of per capita GDP and per capita disposable income. Last, we obtain data of number of high school and faculty-student ratio to control high school education quality, and data of child dependency ratio to control burden of families.

Table 1: Summary Statistics of Key Variables

\begin{tabular}{ccccccc}
\hline Variable & Variable Name & Obs & Mean & Std.Dev. & Min & Max \\
\hline eduyear & Average years of education & 279 & 9.134 & 0.581 & 8.023 & 10.66 \\
eduexp & Per capita education expenditure & 279 & 1528 & 788.5 & 453.8 & 5163 \\
ind & Percentage of industrial sector in GDP & 279 & 46.58 & 8.356 & 19.26 & 61.50 \\
ser & Percentage of service sector in GDP & 279 & 42.75 & 9.261 & 28.60 & 80.23 \\
gdp & Per capita GDP & 279 & 10.52 & 0.516 & 9.085 & 11.68 \\
inc & Per capita disposable income & 279 & 10.30 & 0.405 & 9.525 & 12.93 \\
sci & Per capita expenditure in technology & 279 & 199.6 & 255.3 & 25.32 & 1412 \\
cul & Per capital expenditure in culture and media & 279 & 198.9 & 168.7 & 39.73 & 1074 \\
soc & Per capita expenditure in social security and & 279 & 1173 & 741.5 & 267.8 & 6298 \\
& employment & & & & & \\
tra & Per capita expenditure in transportation & 279 & 712.2 & 773.2 & 31.90 & 6359 \\
pub & Per capita expenditure in general public services & 279 & 981.6 & 752.5 & 381.7 & 6889 \\
high sch & Quantity of high schools & 279 & 5.895 & 0.764 & 3.135 & 6.938 \\
high sch ratio & Student-Faculty Ratio of high school & 279 & 14.91 & 2.524 & 7.747 & 21.14 \\
child ratio & Child dependency ratio & 155 & 23.06 & 6.620 & 9.600 & 39.57 \\
\hline
\end{tabular}

Table 1 provides summary statistics of the variables used in this study. From the table, we can see that the maximum and minimum values of average years of education (eduyear) are 8.023 and 10.66 respectively, and the standard deviation is 0.581 , which indicates that the data set of average years of education does not constitute a very huge difference. This clustering of data may be explained by China's current nine-year compulsory education policy. However, the maximum and minimum values of education expenditure (eduexp) are 453.8 and 5163 , respectively, and the standard deviation is 1528 , suggesting that government spending on education among provinces are significantly different.

Chart 2: Scatterplot: Intuitive relationship between education expenditure and education level (represented by average years of education)

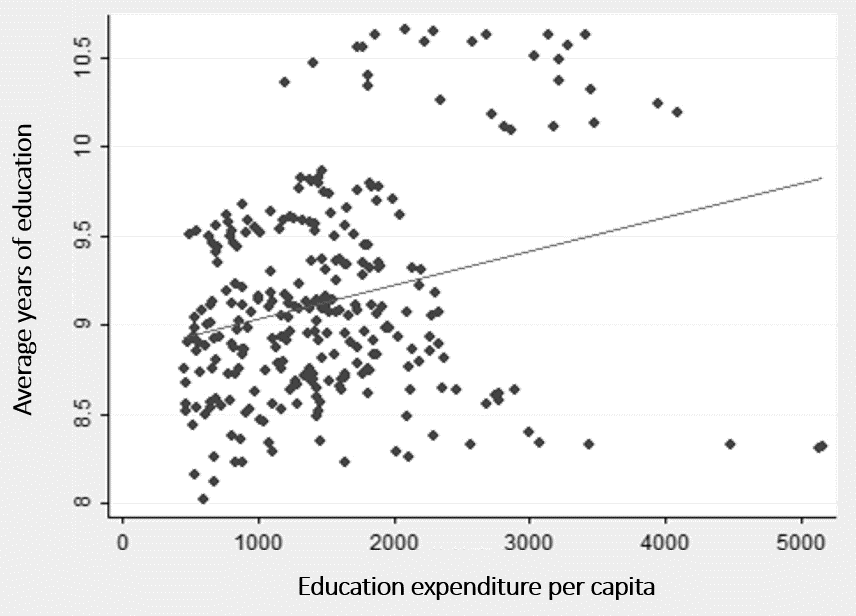




\section{Econometric Model}

\subsection{Empirical Model}

To assess how fiscal expenditure on education influences level of education, we construct the following model.

edu year $_{i t}=\alpha_{0}+\alpha_{1}$ eduexp $_{i t}+\alpha_{2} X_{i t}+\delta_{i}+\mu_{t}+\varepsilon_{i t}$

Subscripts "i" refers to provinces, " $t$ " refers to years. Explained variable "eduyear" delegates the level of education in a given region, and explanatory variable "eduexp" measures the fiscal support of government to education. $X_{i t}$ represents controlled variables, including per capita GDP, GDP percentage of industrial sector, GDP percentage of service sector, population of provinces, school enrolments, quantity of high schools, student-faculty ratio, etc. $\delta_{i}$ and $\mu_{t}$ capture province fixed effect and year fixed effect respectively. Last, $\varepsilon_{i t}$ is the random disturbances, or error term.

\subsection{Baseline Specification and Results}

According to the econometric model, we examine the correlation in a benchmark regression. Starting from the simplest version in column $1 \& 2$, we take more variables into the model -economic development level, industrial structures, expenditure structures, and education quality level. In the last column, random effects model is employed to estimate the sensitivity of the results.

The results show that the per capita education expenditure coefficient is significantly positive, and the correlation is significant under a $5 \%$ significant level even when controlled variables are taken into account.

Therefore, the regression result verified our hypothesis: increases in education expenditure would lead to increases in average level of education. On average, when 1000RMB per capita is spent on education, the level of education would increase by 0.1 year.

Table 2: Baseline Regression Results

\begin{tabular}{|c|c|c|c|c|c|c|}
\hline & (1) & (2) & (3) & (4) & (5) & (6) \\
\hline & eduyear $_{i t}$ & eduyear $_{i t}$ & eduyear $_{i t}$ & eduyear $_{i t}$ & eduyear $_{i t}$ & eduyear $_{i t}$ \\
\hline eduexp $_{i t}$ & $0.000191^{*+*}$ & $0.0000881^{\text {tw*t }}$ & $0.0001000^{\text {tatk }}$ & $0.000138^{\text {ntw }}$ & $0.000127^{* *}$ & 0.0000572 \\
\hline & (4.46) & (5.97) & $(3.06)$ & (2.67) & (2.44) & (1.02) \\
\hline $\operatorname{gdp}_{i t}$ & & & -0.0309 & 0.0176 & -0.00293 & 0.0233 \\
\hline & & & $(-1.86)$ & $(0.86)$ & $(-0.13)$ & $(1.03)$ \\
\hline $\operatorname{ind}_{i t}$ & & & $1.955^{* *}$ & 1.206 & 1.102 & $3.050^{* * * *}$ \\
\hline & & & (2.42) & (1.50) & (1.38) & $(4.04)$ \\
\hline $\operatorname{ser}_{i t}$ & & & $2.431^{*+*+}$ & $1.675^{*}$ & $1.436^{*}$ & $3.574^{\text {tat }}$ \\
\hline & & & (2.80) & (1.98) & (1.68) & $(4.44)$ \\
\hline $\operatorname{sci}_{i t}$ & & & & $\begin{array}{l}-0.000693^{\text {t*t+ }} \\
(-4.66)\end{array}$ & $\begin{array}{l}-0.000647^{*+1+} \\
(-4.33)\end{array}$ & $\begin{array}{l}-0.000425^{* * *} \\
(-2.74)\end{array}$ \\
\hline $\operatorname{cul}_{i t}$ & & & & $-0.000509^{* *}$ & $-0.000457^{* *}$ & $-0.000451^{*}$ \\
\hline & & & & $(-2.43)$ & $(-2.18)$ & $(-1.95)$ \\
\hline soc $_{i t}$ & & & & 0.00000648 & 0.00000855 & 0.00000396 \\
\hline & & & & $(0.21)$ & $(0.27)$ & $(0.11)$ \\
\hline $\operatorname{tra}_{i t}$ & & & & $0.0000697^{* *}$ & $0.0000606^{*}$ & 0.0000608 \\
\hline & & & & (2.01) & (1.75) & (1.58) \\
\hline $\mathrm{pub}_{i t}$ & & & & -0.0000378 & -0.0000212 & -0.0000378 \\
\hline & & & & $(-0.87)$ & $(-0.48)$ & $(-0.81)$ \\
\hline high sch ${ }_{i t}$ & & & & & $-0.305^{*}$ & 0.0239 \\
\hline & & & & & $(-1.88)$ & $(0.32)$ \\
\hline high ratio $i t$ & & & & & -0.0131 & -0.0116 \\
\hline & & & & & $(-1.27)$ & $(-1.02)$ \\
\hline _cons & $8.843^{*+*}$ & $8.999^{*+* t}$ & $7.161^{1 * *}$ & $7.790^{\circ+*}$ & $10.01^{\text {t** }}$ & $6.195^{+* *}$ \\
\hline
\end{tabular}


$(120.32) \quad(375.80) \quad(10.01)$

\begin{tabular}{lllllll}
\hline Year fixed effect & NO & YES & YES & YES & YES & RE \\
Province fixed effect & NO & YES & YES & YES & YES & RE \\
Observed value & 279 & 279 & 279 & 279 & 279 & 279 \\
With $R^{2}$ & 0.0669 & 0.1260 & 0.1590 & 0.2750 & 0.2910 & 0.2347 \\
\hline
\end{tabular}

Note: Values in brackets are $t$-values. ${ }^{* * * *},{ }^{* * * \prime}$ and (*' denote significant results at $1 \%, 5 \%$ and $10 \%$ significance level respectively

\subsection{Robustness Check}

In order to better understand the relationship between education expenditure and level of education, we perform a robustness check of the previous regression results.

As we consider per capita disposable income and child dependency ratio potentially have an influence on our result, we take these two factors respectively into our model.

When per capita disposable income is added, the correlation is still significant under $10 \%$ significant level; when child dependency level is added, the correlation is significant under $5 \%$ significant level.

Thus, we conclude our regression result is robust.

Table 3: Regressions for Robustness Checks

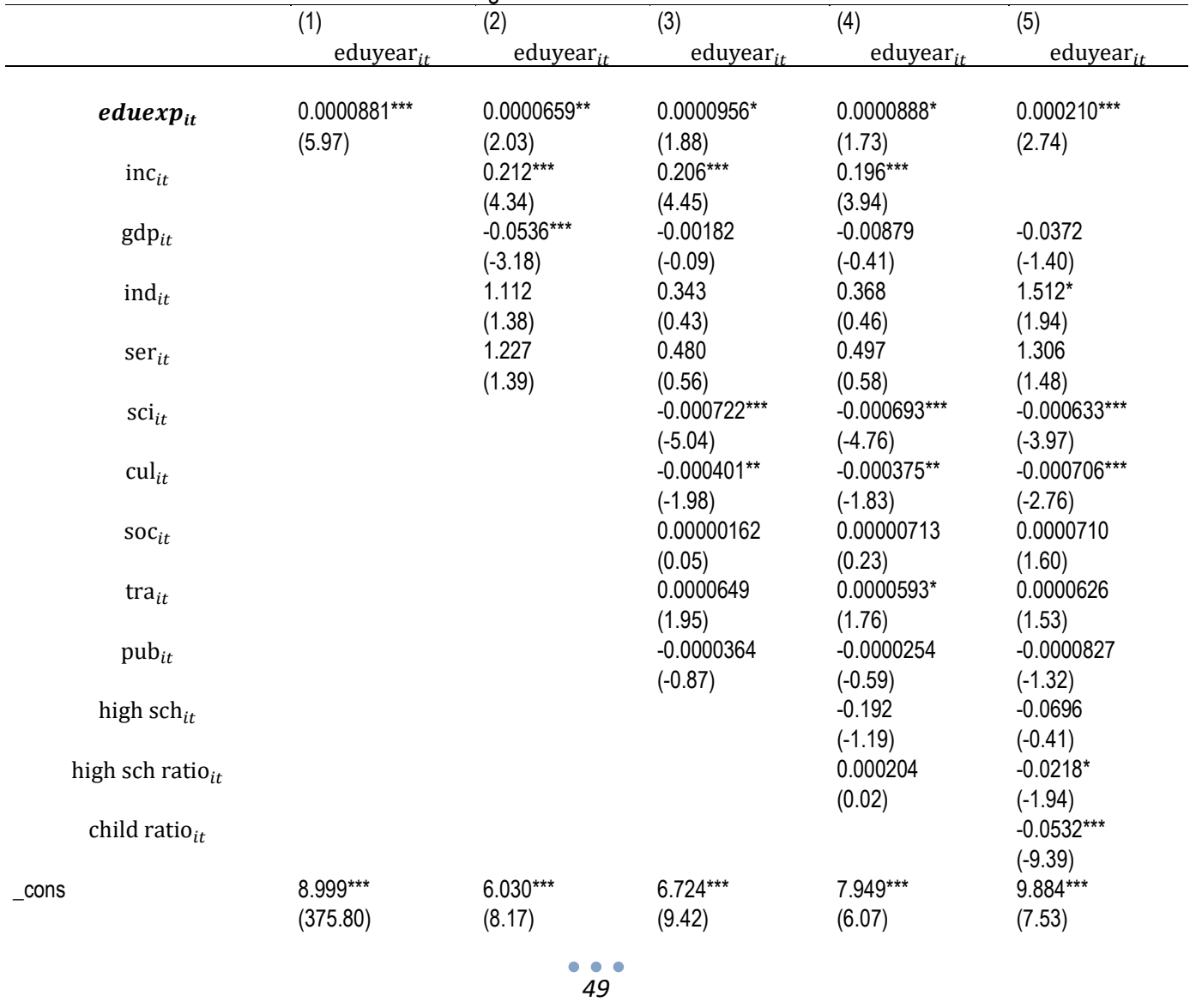




\begin{tabular}{|c|c|c|c|c|c|}
\hline Year fixed effect & YES & YES & YES & YES & YES \\
\hline Province fixed effect & YES & YES & YES & YES & YES \\
\hline Observed value & 279 & 279 & 279 & 279 & 155 \\
\hline With $R^{2}$ & 0.1260 & 0.2194 & 0.3307 & 0.3347 & 0.6881 \\
\hline
\end{tabular}

Note: Values in brackets are $t$-values. ${ }^{* * * *},{ }^{* * * \prime}$ and ${ }^{(* \prime}$ denote significant results at $1 \%, 5 \%$ and $10 \%$ significance level respectively

\section{Further Analysis}

With China commanding around 9.6 square kilometers of land, the vastness of the nation has given rise to remarkable heterogeneity across regions as well as pronounced divergence in economic development. Policies during the early stage of the Reform and Opening-up Campaign also gave rise to the development of cities and special economic zones in eastern coastal regions, creating a gap of economic development between eastern and western region of China ${ }^{[3]}$. Due to this regional heterogeneity, the relationship between fiscal spending and education quality may exhibit different patterns in different areas, we thus further examine our data by splitting our samples into ones from eastern region and the other from non-eastern region.

The result shows that in more developed eastern regions, the education expenditure has already exceeded a certain level, so increases the education expenditure do not significantly increase level of education.

Table 4: Regression Results for Eastern Regions

\begin{tabular}{|c|c|c|c|c|}
\hline & (1) & (2) & (3) & (4) \\
\hline & eduyear $_{i t}$ & eduyear $_{i t}$ & eduyear $_{i t}$ & eduyear $_{i t}$ \\
\hline \multirow{2}{*}{$\operatorname{eduexp}_{i t}$} & $-0.000066^{* *}$ & -0.000088 & 0.000018 & 0.000035 \\
\hline & $(-2.89)$ & $(-1.12)$ & $(0.20)$ & $(0.39)$ \\
\hline \multirow[t]{2}{*}{$\operatorname{gdp}_{i t}$} & & -0.0246 & -0.0280 & 0.00100 \\
\hline & & $(-0.82)$ & $(-0.91)$ & $(0.03)$ \\
\hline \multirow[t]{2}{*}{$\operatorname{ind}_{i t}$} & & $6.229^{* *}$ & 4.106 & 3.620 \\
\hline & & (3.35) & $(1.68)$ & (1.51) \\
\hline \multirow[t]{2}{*}{$\operatorname{ser}_{i t}$} & & $6.707^{+*+t}$ & $4.105^{*}$ & $4.207^{*}$ \\
\hline & & (3.64) & $(1.74)$ & $(1.81)$ \\
\hline \multirow[t]{2}{*}{$\operatorname{sci}_{i t}$} & & & -0.00015 & -0.00021 \\
\hline & & & $(-0.78)$ & $(-1.07)$ \\
\hline \multirow[t]{2}{*}{$\mathrm{cul}_{i t}$} & & & $-0.00086^{*}$ & $-0.00091^{* *}$ \\
\hline & & & $(-2.50)$ & $(-2.69)$ \\
\hline \multirow[t]{2}{*}{$\operatorname{soc}_{i t}$} & & & 0.00007 & 0.000035 \\
\hline & & & $(0.98)$ & $(0.50)$ \\
\hline \multirow[t]{2}{*}{$\operatorname{tra}_{i t}$} & & & 0.00005 & 0.00004 \\
\hline & & & $(0.70)$ & $(0.60)$ \\
\hline \multirow[t]{2}{*}{$\operatorname{pub}_{i t}$} & & & 0.00010 & 0.00019 \\
\hline & & & $(0.58)$ & $(1.10)$ \\
\hline \multirow[t]{2}{*}{ high sch ${ }_{i t}$} & & & & 0.535 \\
\hline & & & & (1.69) \\
\hline \multirow[t]{2}{*}{ high ratio ${ }_{i t}$} & & & & 0.0339 \\
\hline & & & & $(1.65)$ \\
\hline \multirow[t]{2}{*}{ _cons } & $9.591^{*+*+}$ & $3.788^{*}$ & $5.867^{* *}$ & 2.166 \\
\hline & $(231.86)$ & (2.26) & $(2.74)$ & $(0.80)$ \\
\hline Year fixed effect & YES & YES & YES & YES \\
\hline Province fixed effect & YES & YES & YES & YES \\
\hline
\end{tabular}




$\begin{array}{lllll}\text { Observed value } & 99 & 99 & 99 & 99 \\ \text { Within } R^{2} & 0.0874 & 0.2204 & 0.3050 & 0.3599\end{array}$

Note: Values in brackets are t-values. "***', "**' and '**' denote significant results at $1 \%, 5 \%$ and $10 \%$ significance level respectively

Meanwhile, in the western regions, which is comparatively less developed, the correlation between fiscal expenditure on education and level of education is still very significant. We estimate, when 1000RMB per capita is spent on education in western regions, the level of education would increase by 0.4 year, much higher than the average 0.1 year for the entire country.

Considering the controlled variables, we discover the rise of GDP in western region of China is positively related to rise of education level. It implies that in the western region, policies that focus on stimulating economic development would propel the rise in education level as well.

Table 5: Regression Results for Western Regions

\begin{tabular}{|c|c|c|c|c|}
\hline & (5) & (6) & (7) & (8) \\
\hline & eduyear $_{i t}$ & eduyear $_{i t}$ & eduyear $_{i t}$ & eduyear $_{i t}$ \\
\hline eduexp $_{i t}$ & $0.00017^{\star \star *}$ & 0.00041 & $0.00035^{\star \star}$ & $0.00043^{* *}$ \\
\hline & $(11.47)$ & $(1.53)$ & (2.05) & $(1.99)$ \\
\hline $\operatorname{gdp}_{i t}$ & & $0.103^{* \star *}$ & $0.0911^{* * *}$ & $0.0871^{* *}$ \\
\hline & & $(5.76)$ & (3.79) & $(3.27)$ \\
\hline $\operatorname{ind}_{i t}$ & & $-1.620^{* *}$ & $-1.465^{\star *}$ & $-1.446^{\star}$ \\
\hline & & $(-2.31)$ & $(-1.99)$ & $(-1.95)$ \\
\hline $\operatorname{ser}_{i t}$ & & $-1.394^{*}$ & -1.183 & -1.169 \\
\hline & & $(-1.81)$ & $(-1.50)$ & $(-1.47)$ \\
\hline $\operatorname{sci}_{i t}$ & & & 0.00011 & 0.00010 \\
\hline & & & $(0.42)$ & $(0.37)$ \\
\hline $\mathrm{cul}_{i t}$ & & & -0.00015 & -0.00014 \\
\hline & & & $(-0.61)$ & $(-0.55)$ \\
\hline $\operatorname{soc}_{i t}$ & & & -0.00004 & -0.00004 \\
\hline & & & $(-1.35)$ & $(-1.23)$ \\
\hline $\operatorname{tra}_{i t}$ & & & 0.00002 & 0.00002 \\
\hline & & & $(0.65)$ & $(0.54)$ \\
\hline $\operatorname{pub}_{i t}$ & & & -0.00003 & -0.00003 \\
\hline & & & $(-0.77)$ & $(-0.61)$ \\
\hline high sch ${ }_{i t}$ & & & & -0.0877 \\
\hline & & & & $(-0.53)$ \\
\hline high ratio $_{i t}$ & & & & 0.00113 \\
\hline & & & & $(0.11)$ \\
\hline _cons & $8.695^{* \star *}$ & $9.889^{* * *}$ & $9.761^{* * *}$ & $10.25^{* * *}$ \\
\hline & (372.89) & $(16.23)$ & $(15.54)$ & $(8.67)$ \\
\hline Year fixed effect & YES & YES & YES & YES \\
\hline Province fixed effect & YES & YES & YES & YES \\
\hline Observed value & 180 & 180 & 180 & 180 \\
\hline Within $R^{2}$ & 0.4527 & 0.5730 & 0.5862 & 0.5871 \\
\hline
\end{tabular}

Note: Values in brackets are $t$-values. "***', "**' and '*' denote significant results at $1 \%, 5 \%$ and $10 \%$ significance level respectively 


\section{Conclusion}

In an attempt to clarify the relationship between fiscal expenditure on education and level of education, and to answer the question whether increasing education expenditure is constantly an effective stimulus to education level release by government, we built our econometric model by gathering a set of panel data -- concerning education level and quality, economic development level, and other social factors ranging from 2008 to 2016.

Based on the data we examined in the study, we first concluded that education expenditure is generally positively correlated with level of education, and is subject to the minor influence from economic development level, expenditure structures, and teaching quality.

However, owing to China's remarkable heterogeneity, as we further explored the issue by separating data, the data set reveals the key correlation discussed is significant in less developed western regions of China, but insignificant in more developed eastern regions.

Such results may imply expanding fiscal expenditure in western regions would be more efficient for the government to raise provincial education quality, and similar policy instrument may apply to other less developed regions of the country. Meanwhile, fiscal policy would be less efficient to raise education quality in more developed eastern area. To further elevate level of education in economic developed regions, governments are advised to consider alternative approaches, and thus new policy instrument is necessary.

\section{References}

[1] National Bureau of Statistics of China, "National Data", data.stats.gov.cn/easyquery.htm, accessed on 28-Aug2018

[2] JS Coleman, "Social Capital in the Creation of Human Capital", The American Journal of Sociology, 1998, Vol. 94

[3] S Black and L Lynch, "Human-Capital Investments and Productivity", American Economic Review, 1996, Vol. 86, issue 2, 263-67

[4] E Cannon, "Human capital: level versus growth effects", Oxford Economic Papers, 2000, Vol. 52, issue 4, 670676, doi.org/10.1093/oep/52.4.670, accessed on 2-Sep-2018

[5] R Bundell, L Dearden, C Meghir, B Sianesi, "Human capital investment: the returns from education and training to the individual, the firm and the economy", Fiscal Studies, 1999, Vol. 20, issue 1, 1-23, doi.org/10.1111/j.14755890.1999.tb00001.x, accessed on 2-Sep-2018

[6] S Slaughter, SA Slaugter, G Rhoades, "Academic capitalism and the new economy: Markets, state, and higher education", JHU Press, 2004

[7] C Liu, JM Armer, "Education's effect on economic growth in Taiwan", Comparative Education Review, 1993, Vol. 37, no. 3, journals.uchicago.edu/doi/pdfplus/10.1086/447192, accessed on 2-Sep-2018

[8] JR Reynolds, CE Ross, "Social stratification and health: Education's benefit beyond economic status and social origins", Social Problems, 1998, Vol. 45, issue 2, 221-247

[9] S Gupta, M Verhoeven, ER Tiongson, "The effectiveness of government spending on education and health care in developing and transition economies", 2002, appg-popdevrh.org.uk, accessed on 16-Sep-2018

[10] F Cai, D Wang, Y Du, "Regional disparity and economic growth in China: The impact of labor market distortions", 2002, doi.org/10.1016/S1043-951X(02)00072-X, accessed on 17-Sep-2018 